\title{
Exploration and practice of training mode of engineering talents based on open online courses
}

\author{
Shue $\mathrm{Liu}^{1}$, Zonghua $\mathrm{Gao}^{1}$ and Dashe $\mathrm{Li}^{2}$,* \\ ${ }^{1}$ Binzhou Medical University, Yantai, China \\ ${ }^{2}$ Shandong Technology and Business University, Yantai, China
}

Keywords: Engineering talents, Open online courses, Map of hourglass.

\begin{abstract}
As Chinese economy changes from rapid-speed growth to superior-quality development mods, cultivating the talents for the emerging industries must keep up with The Times to make corresponding adjustments, as well as based on information technology, adopting the multi-paradigm training mode to cultivate amounts of the new engineering talents with cross-knowledge system and innovation. This paper discusses how to take advantage of the creative knowledge map of hourglass to rapidly promote students' professional ability and the cultivation of their innovation in virtue of online courses, and finally comes to an exploration model.
\end{abstract}

\section{Introduction}

Chinese economic is undergoing a critical period of structural adjustment, transformation and upgrading, changing from a rapid growth to a high-quality stage. Set in background of the rapid development of the new round of scientific and technological revolution and industrial revolution worldwide, higher education in China is bound to enter a new stage with economic development. It is urgent to cultivate a large number of diversified, innovative and outstanding engineering talents in the new era of engineering. The Ministry of Education held a seminar on the strategy of higher engineering education in Fudan University on February 18th, 2017. The participating universities had a heated discussion on the training of engineering talents in the new era, and jointly discussed the connotation characteristics and the path selection of construction and development of the new engineering ${ }^{[1]}$. The Ministry of Education held a seminar on new engineering construction in Tianjin university on April 8, 2017 .More than 60 universities discussed the vision and action of new engineering construction. The participants all agreed that it is obvious that cultivating a large number of diversified, innovative and outstanding engineering and scientific talents to provide intellectual and talent support for Chinese industrial development and international competition is both an urgent matter and a long-term solution ${ }^{[2]}$. The Ministry of Education

\footnotetext{
*Corresponding author: lidashe@126.com
} 
held the establishment of the new engineering research and practice expert group and the first working meeting in Beijing on June 9, 2017, aiming to fully start and systematically deploy the new engineering construction. More than 30 experts from universities, enterprises and research institutions deeply discussed the new opportunities brought by the industrial revolution, focused on the new needs of the country, planned the new development of engineering education, deliberated and passed the New Engineering Research and Practice Project Guide, and put forward opinions on constructing new engineering. The consensus made in Fudan university, the action taken by Tianjin university and the guide of Beijing constitute the Trilogy of constructing the new engineering, playing the main melody of talent training and opening up a new path of engineering education reform.

The Ministry of Education, the Ministry of Industry and Information Technology and the Chinese Academy of Engineering jointly issued the opinions on accelerating the construction and development of new engineering projects and implementing the excellent engineer education and training plan 2.0 on September 17, 2018, which pointed out that it is essential to adapt to the new round of scientific and technological revolution and the new trend of industrial transformation, and closely focus on the national strategy and regional development needs, considering joining international engineering education in the Washington agreement organization as an opportunity to new engineering construction, continue to deepen reform of engineering education and speed up to train and lead a new round of technological revolution and industrial revolution of engineering science and technology talents, build the engineering innovation center and talent highland, and finally improve national strength and international competitive.

\section{Training objectives of engineering talents}

According to the report Engineering Education in a Rapidly Changing from Delft Institute of Technology in 2014, the future Engineering Education mainly includes the following key aspects:Engineering preciseness, critical thinking and non-standardized problem solving, interdisciplinary and systematic thinking, imagination, creativity, initiative, communication and cooperation, global thinking model, diversity and mobility, student participation and professional learning community, employment and lifelong-learning [3].

Certification association of the Chinese engineering education set in the 2018 edition - the Engineering Education Accreditation Standards asked the requirements for undergraduates, respectively from the following 12 aspects: engineering knowledge, problem analysis, solution design/development, research, engineering, using modern tools and society, environment and sustainable development, professional norms, individual and team, communication, the project management and lifelong learning.For engineering students, they should be able to apply mathematics, natural science, engineering fundamentals and professional knowledge to solve complex engineering problems, and develop, select and use appropriate technologies, resources, modern engineering tools and information technology tools to analyze and solve complex engineering problems based on scientific principles.

For engineering students, set in the new characteristic of the Internet integration, data actuation, software definition, platform support, the intelligent- oriented growing economy era,aiming to be equipped with the core competitiveness, they need to have some basic knowledge, global mindset self-service, deep learning paradigm based on different professional background, form the discipline of harmony, so as to solve complex problems, which poses a challenge to cultivating engineering students.It is obvious that those are problems that need to be considered, considering how to make better use of resources, the integration of teachers, the construction of online open courses, the teaching mode and the way of practical training all need to be improved based on the existing conditions. 
It is necessary to design in relation to the relevant factors of the university education system in order to cultivate innovative talents with rigorous engineering, critical thinking and lifelong learning ability in the new data-driven era. The key elements of university education system include universities, departments and talent cultivation system, teachers and teaching system, knowledge system and curriculum system, teaching resource system, teaching management system, quality and evaluation system, engineering education certification system, innovation and entrepreneurship practice system, etc.In order to build a high-quality new engineering talent cultivating system, it is necessary to design closely refers to these key elements [4].

\section{Emerging engineering education in online open courses}

\subsection{Faculty}

The call on diversified and innovative engineering talents entails us to equip teachers with cutting-edge research level in a particular discipline and foster a first-class teacher team that is multi-disciplinary integrated to teach students with top quality. The teaching resources, once limited in the past, was unleashed its potential as it has been shared in the era of network information. Various courses, by taking advantage of online open access, have broke the intra-school and inter-school barriers, achieving the optimal allocation of teaching resources. At the same time, students from different majors can study across disciplines and be accredited with academic credits by searching for courses that capture their attention.

Furthermore, what embedded in mixed teaching is the offline questions answering and guidance to students besides online teaching. Therefore, it is pivotal to train teachers in both their professionalism foundation and educational philosophy, as well as teaching capability: First, equip teachers with advanced teaching concepts and methods by sending them to participate in high-level meetings of innovative talent training; The second is to encourage teachers to participate in some innovative subject competitions to enhance teachers' guidance and counseling skills for specific problems. Third, encourage teachers from different disciplines to form scientific research teams, hence shaping a cross-composite of engineering and cross-integration between engineering and other disciplines; The fourth is motivate teachers and industry talents to exchange within the industry, thereby enhancing the understanding of the theory and practical ability; The fifth is to elevate the international vision of teachers and achieve international exchanges by sending teachers to visit abroad.

\subsection{Curriculum resource construction}

For undergraduate engineering students, they initially formed the cognition towards engineering at the beginning of their freshman year and is upheld thereafter until graduation. In a short period of four years, as a new force of innovation and entrepreneurship, students would learn to search for and obtain knowledge points of interest in the huge knowledge system, making it difficult to form a complete knowledge system and learning path planning. Moreover, restricted by the professional perspective, it is difficult for students to follow up with the industrial trend and spontaneously establish a professional knowledge system of their own. Relying on the professional teacher team from a global perspective and on the existing professional knowledge map is what we call an effective strategy. This map involves vertical and horizontal knowledge points, even cross-cutting, which can help students effectively select what intrigues their interests and how it will develop, increase the goal and purpose of 
learning, and achieve better interdisciplinary integration and cross-border fusion, which is conducive to students to choose scientific, reasonable and professional training programs according to their own interests, and to effectively and efficiently train students.

\subsection{Convert the thoughts in classrooms}

For emerging engineer education, an innovative teaching mode shall be employed. We must change our concepts, that is, transforming from the receptive and negative teaching to the students-centered active teaching, and guide students to study autonomously and in depth. College students are the post-90s and post-00s generations, who grew up in the digital network era as its aboriginal inhabitants, so they are more accustomed to finding and constructing information in the network environment, which is also flexible, fragmented, networked and multi-dimensional methods popular among young students. Colleges and universities can explore and use emerging educational technologies and methods to meet the learning styles and needs of engineering students, and improve students' self-learning ability and problem-solving ability. Teachers can develop learning tasks and assessment plans for relevant courses, and through the screening of online courses or videos suitable for the course, enable students to use the MOOC platform and online educational videos with rich resources to complete online learning and online resource sharing, self-study, self-assessment, accumulating points, online Q\&A, etc., In addition, through the interactive communication between teachers and students in the online community, the enthusiasm and exploration of students would be mobilized, thus fully expanding the time and space conditions for innovative learning, which is conducive for students to carry out in-depth learning; on the offline aspect, teachers through the classroom Q \& A and organize groups to discuss debates and other forms to complete the students' deep learning and critical thinking. In this way, students can develop their basic knowledge, advanced skills, develop analytical problems, integrate logical thinking and dialectical thinking, and solve core problems. Furthermore, compared with the past, this teaching mode is more in line with the post-90s and post-00s generations, with vitality of teaching added.

\subsection{Create a practical teaching pattern under the virtual environment}

With the rapid development of computer and information technology, the virtualized simulation training environment based on project is playing an increasingly important role. It takes the project as the carrier and has various content forms. It can be a demonstration of the process of project demonstration, program selection and organization and implementation by the $\mathrm{R} \& \mathrm{D}$ team. It can also be a video introduction of a workshop on the production process of a product, or the completion process of representative cash experimental projects in key universities. Students can complete the design, development, commissioning, etc. of the project in groups. For engineering students, the engineering cognition training module developed through the practice teaching links and internships allows students to experience some experimental operations. The specific process of setting up specific scenes can be completed through the simulation experiment platform. The experience is convenient and fast, so that students can develop the operational ability of the students while experiencing the professional behavior of the project, hence benefiting a wide range of facets.

With the rapid development of a new round of scientific and technological revolution and industrial revolution worldwide, China's higher education will inevitably undergo a new stage with economic development. The future engineering talent training should be based on a global vision, active learning, imagination ability and creativity. The engineering talent training model based on online courses can improve students' information literacy, cultivate 
self-learning ability, imagination and creativity of learning, and gradually lead students to form deeper understanding and more advanced thinking skills, so that students can apply what they have learned and skills to real, complex and rapidly changing worlds, be able to discover scientific problems from engineering, and can use scientific principles to solve engineering problems, so as to cultivate a multi-disciplinary and integrated innovation talent suitable for the economic development of the times.

\section{Summary}

A training mode of engineering talents based on open online courses is explored in this paper. Advices on how to take advantage of the creative knowledge map of hourglass to rapidly promote students' professional ability and the cultivation of their innovation in virtue of online are provided.

This research was financially supported by the second batch of industry-university cooperative education project of 2018.

\section{References}

1. Information on http://www.huaxia.com/jtzq/tjxw/2019/04/6094602.html

2. Routes of action on the construction of Emerging Engineering Education (Operation Tianda). Research in Higher Education of Engineering,02(2017), 1-2

3. D. H. Zhong. Connotations and Actions for Establishing the Emerging Engineering Education. Research in Higher Education of Engineering, 03(2017), 1-6

4. X. F. Xu, J. H. Ding. Exploration on the Reform of Talents Training Model for Emerging Engineering Education Facing Sustainable Competitiveness. China University Rducation,6(2017)6-10 